\title{
1 Influence of interleukin-18 polymorphisms on kidney 2 transplantation outcomes: A meta-analysis
}

3

6

13

14

15

16

17

18

19

20

21

22

41

42

\author{
Thanee Eiamsitrakoon ${ }^{1,2}$, PhuntilaTharabenjasin ${ }^{1 *}$, Noel Pabalan ${ }^{1}$, Rungrawee \\ Mongkolrob로 Aporn Bualuang ${ }^{1}$ and Adis Tasanarong ${ }^{1,2}$ \\ ${ }^{1}$ Chulabhorn International College of Medicine, Thammasat University. \\ Cooperative Learning Center, Piyachart 2 Building, 99 Moo 18, Paholyothin Rd., Klong Neung, Klong Luang, Rangsit, \\ Pathumthani 12120 Thailand \\ 2 Nephrology Unit, Faculty of Medicine, Thammasat University. \\ 99/209 Moo 18, Paholyothin Rd., Klong Neung, Klong Luang, Rangsit, Pathumthani 12120 Thailand
}

Thanee Eiamsitrakoon

Email: thaneeeiams@gmail.com

Noel Pabalan

Email: noelpabalan@ymail.com

Rungrawee Mongkolrob

Email: scrmr303@gmail.com

Aporn Bualuang

Email: tent79@hotmail.com

Adis Tasanarong

Email: adis tasanarong@hotmail.com

\section{Corresponding author:}

Phuntila Tharabenjasin ${ }^{1 *}$

Address correspondence to Phuntila Tharabenjasin,

Chulabhorn International College of Medicine, Thammasat University,

Cooperative Learning Center, Piyachart 2 Bulding, 99 Moo 18 Klong Luang, Rangsit, Pathumthani 12120, Thailand

Email: pacezen@yahoo.com

Telephone: (66) 2564-4440-9 Ext 7589 ; (66) 91-959-8915

(iD) orcid.org/0000-0002-4191-2802

\begin{abstract}
Aim: Allograft survival post-kidney transplantation (KT) are in large part attributed to genetics, which render the recipient susceptible or protected from allograft rejection. KT studies involving single nucleotide polymorphisms (SNPs) have reported the association of interleukin-18 (IL-18) with KT and its role in allograft rejection. However, the reported outcomes been inconsistent, prompting a meta-analysis to obtain more precise estimates. Methods: We posed two hypotheses about the IL-18 SNPs: their association with KT (H1), and increase or decrease in the risks of allograft rejection ( $\mathrm{H} 2)$. Using standard genetic models, we estimated odds ratios [ORs] and 95\% confidence intervals by comparing the IL-18 genotypes between two groups: (i) patients and controls for H1 (GD: genotype distribution analysis); (ii) rejectors and non- rejectors for $\mathrm{H} 2$ (allograft analysis). Multiple comparisons were corrected with the Holm-Bonferroni (HB) test. Subgrouping was ethnicity-based (Asians and Caucasians). Heterogeneity was outlier-treated and robustness of outcomes was sensitivity-treated. Results: This metaanalysis generated eight significant outcomes, which HB filtered into four core outcomes, found in the dominant/codominant models. Two of the four were in GD, indicating associations of the IL-18 SNPS with KT (ORs 1.34 to $\left.1.39,95 \% \mathrm{Cls} 1.13-1.70, P_{\mathrm{HB}}=.0007-.004\right)$. The other two were in allograft analysis indicating reduced risk with $\mathrm{HB} P$-values of .03 for overall (OR 0.74, 95\% $\mathrm{Cl} 0.56-0.93$ ) and Asian (OR 0.70, 95\% $\mathrm{Cl} 0.53$ 0.92). In contrast to the protected Asian subgroup, Caucasians showed non-significant increased risk (OR 1.20. $\left.95 \% \mathrm{Cl} .82-1.75, P^{\mathrm{a}}=.35\right)$. Sensitivity treatment conferred robustness to all the core outcomes. Conclusions: Overall association of IL-18 SNPs with KT was significant (up to 1.4-fold) and Asians KT recipients were protected (up to $30 \%$ ). Enabled by outlier treatment, these findings were supported by non-heterogeneity and robustness. More studies may confirm or modify our findings.
\end{abstract}




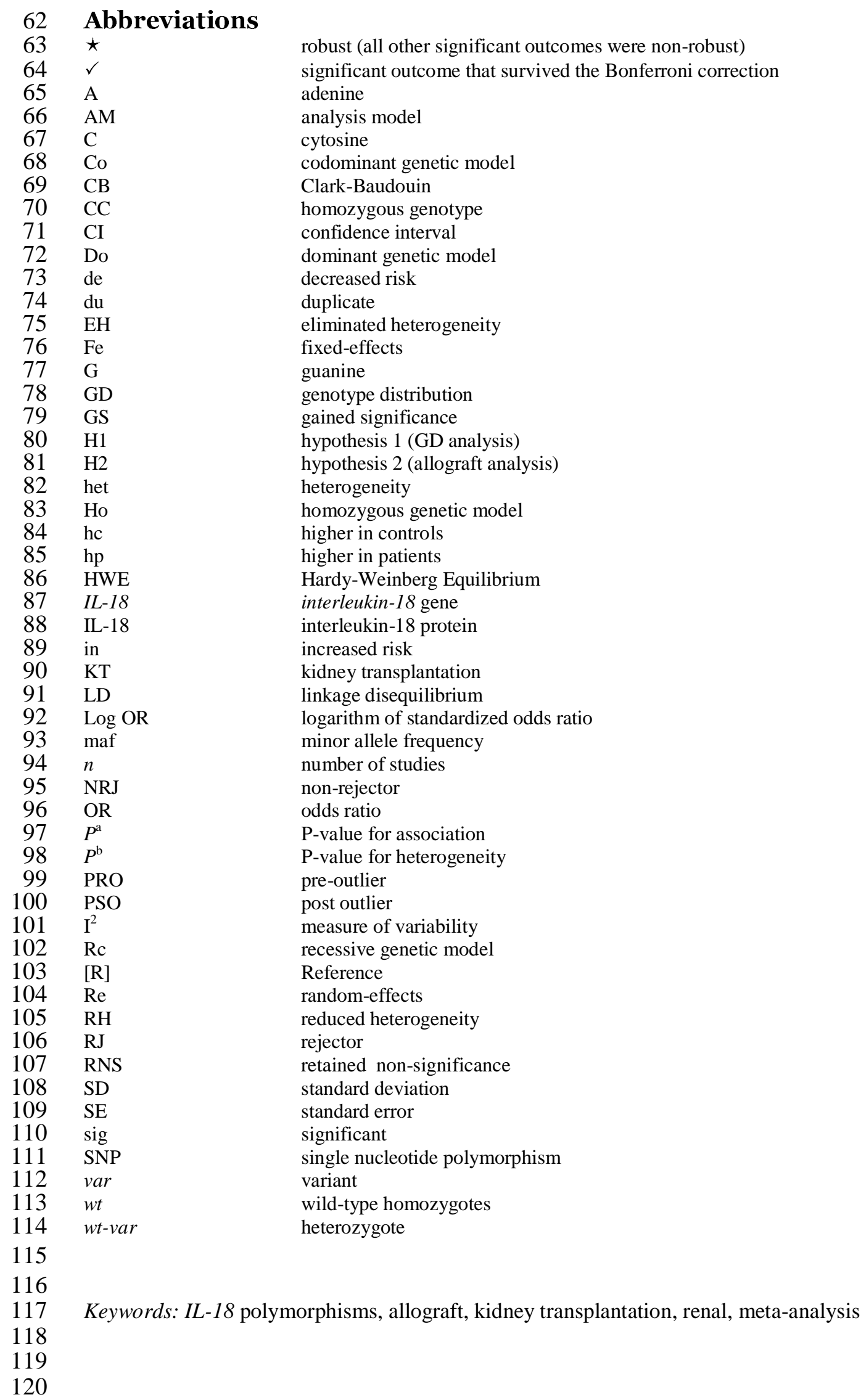


medRxiv preprint doi: https://doi.org/10.1101/2020.05.27.20101196; this version posted June 1, 2020. The copyright holder has placed this

121

122

123

124

125

126

127

128

129

130

131

132 the genetics of KT.

\section{Introduction}

The end-stage of renal failure resulting from kidney disease points to kidney transplantation (KT) as the optimal therapeutic choice [1,2]. The transplanted material (allograft) in the recipient is successful only if it is not rejected [3]. Unrejected allografts are expected to perform the functions as normal kidneys. Normal post-KT graft outcomes depend on immunology where variation in immune responses of the recipient is genetically influenced [4]. This variation may help individualize immunosuppressive regimens by identifying alleles that could increase risk or confer protection for immune-mediated complications [5]. Cytokines are potent immunomodulatory molecules that mediate the immune response [6]. Their production has been shown to be genetically controlled and polymorphisms of many cytokine genes affect their transcriptional activities, resulting in individual variations in cytokine production [7]. Of the cytokine-related factors, interleukin-18 (IL-18) has been identified as a post-KT biomarker [8]. Single nucleotide polymorphisms (SNPs) have been reported to be associated with post-KT outcomes [9]. Studies of $I L-18$ SNP associations with KT outcomes have promoted better understanding of renal disease immunology, providing greater insight into the biology of KT. However, the primary study conclusions have varied in their degree of concurrence. A meta-analysis addressing this variation may yield clearer estimates of the role of $I L-18$ SNPs in KT outcomes. In this meta-analysis, we operated on two hypotheses about the $I L-18$ SNPs, their association with KT (H1), and increase or decrease in the risks of AR (H2). In H1, we examine genotype distribution (GD) between patients and healthy controls. In $\mathrm{H} 2$ allograft analysis, we compare rejector (RJ) with nonrejector (NRJ) patients. Outcomes from this this might provide useful clinical information for 


\section{Methods}

\section{Selection of studies}

We searched MEDLINE using PubMed, Google Scholar and Science Direct for association studies as of September 24, 2019. The terms used were "interleukin", "IL-18”, "cytokine “, "polymorphism", "allograft" and "renal transplantation" as medical subject heading and text. References cited in the retrieved articles were also screened manually to identify additional eligible studies. In cases of duplicate articles, we selected the one with a later date of publication. Inclusion criteria were (1) case-control design evaluating the association between $I L-18$ polymorphisms and KT outcomes. (2) $I L-18$ genotype frequencies that compare KT patients and healthy controls, NR and NRJ. (3) Sufficient genotype frequency data to enable calculation of the odds ratios (ORs) and 95\% confidence intervals (CIs). Exclusion criteria were (1) not involving renal allografts or post-KT outcomes; (2) reviews; (3) not about the $I L-18$ polymorphisms and (4) studies whose genotype or allele frequencies were unusable or absent.

\section{SNP groupings}

The included articles examined two $I L-18$ SNPs, rs 187238 and rs1946518, each presented with genotype data (Tables S2 and S3). Observed phenotypic associations have been attributed to the proximity of two SNPs [10,11]. NCI LDLINK (https://ldlink.nci.nih.gov/) results shows that the two SNPS are in linkage disequilibrium (LD). LD is the correlation between alleles located near each other [12] which is measured in terms of $\mathrm{D}^{\prime}$ with a value of 1 indicating complete LD [13]. Therefore, $I L-18$ SNPs (rs 187238 and rs1946518) with D' values of 1.00 in this study (Table S1) were combined in the analysis (Tables S2 and S3). The rationale for combining rests on the assumption that SNPs in LD yield similar associations in the phenotype. 
medRxiv preprint doi: https://doi.org/10.1101/2020.05.27.20101196; this version posted June 1, 2020. The copyright holder has placed this

\section{Data extraction, HWE and methodological quality}

177 Two investigators (TE and NP) independently extracted data and arrived at a consensus. The

178 following information was obtained from each publication: first author's name, year of the

179 study, country of origin, ethnicity, age of the subjects in years, IL-18 SNPs (rs number)

180 (Table 1). Sample sizes as well as genotype data between the RJ and NRJ were also extracted

181 along with calculated outcome of the minor allele frequency (maf) (Tables S2 and S3). The

182 Hardy-Weinberg Equilibrium (HWE) was assessed using the application in

183 https://ihg.gsf.de/cgi-bin/hw/hwa1.pl. The Clark-Baudouin (CB) scale was used to evaluate

184 methodological quality of the included studies [14]. CB criteria include $P$-values, statistical

185 power, correction for multiplicity, comparative sample sizes between cases and controls,

186 genotyping methods and the HWE. In this scale, low, moderate and high have scores of $<5$,

$187 \quad 5-6$ and $\geq 7$, respectively.

\section{Meta-analysis}

We estimated ORs and $95 \%$ CIs using two overall approaches: (i) genotype distribution (GD) between cases and healthy controls and (ii) allograft wherein RJ were compared with NRJ. Thus, both were KT outcomes were analysed separately. Calculated pooled ORs for GD were either higher in patients (hp) or higher in controls (hc); in allograft, they were either increased (in) or decreased (de), indicating risk for rejection. Standard genetic modeling was used, wherein we compared the following, (i) recessive (Rc: wt-wt versus $w t$-var $+v a r$-var), (ii) dominant (Do: $w t-w t+w t$-var versus var-var) and (iii) codominant (Co: wt versus var) effects. Heterogeneity between studies was estimated with the $\chi^{2}$-based Q test [15], with threshold of significance set at $P^{\mathrm{b}}<.10$. Heterogeneity was also quantified with the $\mathrm{I}^{2}$ statistic which measures variability between studies [16]. Evidence of functional similarities in population features of the studies warranted using the fixed-effects model [17], otherwise the random-effects model [18] was used. Sources of heterogeneity were detected with the 
medRxiv preprint doi: https://doi.org/10.1101/2020.05.27.20101196; this version posted June 1, 2020. The copyright holder has placed this

202 Galbraith plot [19] followed by re-analysis (outlier treatment). Of note, outlier treatment

203 dichotomized the comparisons into pre-outlier (PRO) and post-outlier (PSO). Sensitivity

204 analysis, which involves omitting one study at a time and recalculating the pooled OR, was

205 used to test for robustness of the summary effects. The low number of studies precluded

206 assessment of publication bias. Multiple associative outcomes were Holm-Bonferroni (HB)

207 corrected. Data were analysed using Review Manager 5.3 (Cochrane Collaboration, Oxford,

208 England), SIGMAPLOT 11.0 and SIGMASTAT 2.03 (Systat Software, San Jose, CA, USA).

209

210

211

212

213

\section{Results}

\section{Search outcomes and study features}

Figure 1 outlines the study selection process in a PRISMA-sanctioned flowchart (Preferred

215 Reporting Items for Systematic Reviews and Meta-Analyses). Initial search resulted in 39

216 citations, followed by a series of omissions that eventually yielded four articles for inclusion

217 [20-23]. Table 1 shows two Asian [20,21] and two Caucasian [23,22] articles with middle-

218 age profile of the KT subjects (mean \pm SD: 37.8 years \pm 5.9 ). Three $[23,22,21]$ of the four

219 included articles examined the two $I L-18$ polymorphisms (rs 187238 and rs 1946518).

220 Methodological quality of the component studies was moderate with a mean \pm SD of $6.37 \pm$

221 1.24. Tables S2 and S3 show seven studies each for GD and allograft analyses. This meta-

222 analysis followed the PRISMA guidelines (Table S5).

\section{Meta-analysis outcomes}

224

Table 2 delineates the overall pooled ORs by direction of effect, where GDs were higher in patients $(h p)(\mathrm{OR}>1.00)$ but decreased risk $(d e)$ in the allograft analysis $(\mathrm{OR}<1.00)$. The results generated 27 comparisons (Tables 2-3), eight of which were statistically significant $\left(P^{\mathrm{a}}<.05\right)$. Of the eight, four withstood the HB correction, which were considered the core findings. Of the four, two were in GD showing $h p$ effects in the Do/Co models (OR 1.34- 
medRxiv preprint doi: https://doi.org/10.1101/2020.05.27.20101196; this version posted June 1, 2020. The copyright holder has placed this

preprint (which was not certified by peer review) in the Public Domain. It is no longer restricted by copyright. Anyone can legally share, reuse, remix, or adapt this material for any purpose without crediting the original authors.

$2301.39,95 \%$ CIs 1.13 to $\left.1.70, P_{\mathrm{HB}}=.0007-.004\right)$. The other two core outcomes (at HB $P$-values

231 of .03) were in allograft analysis indicating reduced risk in the Co model, one in the overall

232 (OR 0.73, 95\% CI 0.56-0.93) and the other in Asians (OR 0.70, 95\% CI 0.53-0.92). This

233 Asian contrasted with the increased risk outcome in Caucasians (OR 1.20, 95\% CI 0.82-1.75,

$\left.234 \quad \mathrm{P}^{\mathrm{a}}=0.35\right)$

235

236 Of note, all four core outcomes were outlier-derived (PSO). The mechanism of outlier

237 treatment for $I L-18$ in the Co model of allograft analysis is visualized in Figures 2-4. Figure 2

238 shows the PRO forest plot with a non-significant $\left(P^{\mathrm{a}}=.48\right)$ and heterogeneous $\left(P^{\mathrm{b}}=.02, \mathrm{I}^{2}=\right.$

$23960 \%$ ) pooled effect indicating reduced risk (OR $0.8995 \%$ CI 0.63 to 1.25 ). The Galbraith

240 plot identified the two studies [22,21] as the sources of heterogeneity (outliers), located above

241 the +2 confidence limit (Figure 3). In Figure 4, the PSO outcome (outliers omitted) shows

242 reduced heterogeneity $\left(P^{\mathrm{b}}=.16, \mathrm{I}^{2}=39 \%\right)$; reduced risk effect (OR $0.7395 \%$ CI 0.56 to

$2430.93)$ and gained significance $\left(P^{\mathrm{a}}=.01\right)$. This operation is numerically summarized in Table

244 2. Sensitivity treatment deemed the core outcomes to be robust.

\section{Discussion}

248 The main findings of this study showed that $I L-18$ SNPs were associated with KT outcomes,

249 more specifically, the allograft analysis indicated reduced risks of rejection. Subgroup

250 analysis identified Asian KT recipients with the IL-18 SNPs as protected from allograft

251 rejection which contrasted with the increased risk for the Caucasian subgroup. The core status

252 of having withstood $\mathrm{HB}$ and robustness of our principal findings underpin the strength of

253 evidence in this study. Furthermore, outlier treatment unraveled significant and non-

254 heterogeneous associations that were not present in the component single-study outcomes.

255 Conflicting outcomes between primary studies may be attributed to their lack of power and 
medRxiv preprint doi: https://doi.org/10.1101/2020.05.27.20101196; this version posted June 1, 2020. The copyright holder has placed this

256 small sample sizes. Underpowered outcomes appear to be common in candidate gene studies

257 [24] and are prone to the risk of Type 1 error. In spite of the evidence for associations, the

258 complexity of allograft rejection involves interactions between genetic and non-genetic

259 factors allowing for the possibility of environmental involvement. Gene-gene and gene-

260 environment interactions have been reported to have roles in associations of other

261 polymorphisms with post-KT allograft rejection. One article [21] examined another gene

262 polymorphism (vascular endothelial growth factor $(V E G F)$. All articles acknowledged gene-

263 environment interaction. Addressing gene-gene and gene-environment interactions may help

264 address the pathophysiological significance of $I L-18$ in allograft failure post-KT. All the

265 included articles mentioned haplotype analysis with one presenting haplotype data [21].

266 Focus on $I L-18$ haplotypes have been suggested for future association studies [9].

267 The crucial role of $I L-18$ in kidney physiology lies in its involvement in the filtration,

268 integrity and permeability of the glomerular basement membrane [25]. IL-18 expression in

269 the renal epithelium might be important in triggering specific immune response manifested as

270 acute graft rejection [26]. Increased IL-18 production promotes enhanced endothelial

271 permeability and augmented leukocyte migration into the allograft, promoting a clinically

272 recognized rejection episode [21]. A study demonstrated upregulation of IL-18 production in

273 patients with acute rejection of kidney allograft [26]. Moreover, another study found

274 significantly higher levels of IL-18 in culture biopsies from patients with acute rejection in

275 comparison to stable KT patients [27]. Urinary IL-18 has been found to be an early,

276 noninvasive and accurate predictor for dialysis within the first week of KT [28].

280 Two strengths of our study were: (i) outlier treatment was key to generating significance and

281 reducing heterogeneity; and (ii) subgrouping identified Asians as significantly protected and 
medRxiv preprint doi: https://doi.org/10.1101/2020.05.27.20101196; this version posted June 1, 2020. The copyright holder has placed this

preprint (which was not certified by peer review) in the Public Domain. It is no longer restricted by copyright. Anyone can legally share, reuse, remix, or adapt this material for any purpose without crediting the original authors.

282 Caucasians as non-significantly susceptible to allograft rejection. Limitations include: (i) the

283 component studies were underpowered, however, sample sizes were adequate at the

284 aggregate level with 624 cases/634 controls in GD (Table S2) and 147 cases/674 controls in

285 allograft (Table S3). (ii) Genotype distributions of the control population in some studies

286 deviated from the HWE (Tables S2 and S3) and it might be a source of potential bias in our

287 study.

288 6. Conclusions

289 To our knowledge, this is the first meta-analysis with evidence that may render $I L-18$ useful

290 as a prognostic marker in allograft rejection post-KT. Additional well-designed studies

291 exploring other parameters may confirm or modify our results in this study.

292

293

Conflict of interest

294

295

296

The authors have no conflicts of interest to declare

\section{Funding}

None

298

299

300

301

302

303

304

305

306

307

308

309

310

\section{Supporting information}

Table S1

Table S2

Table S3

Table S4
LD matrix

Quantitative features GD

Quantitative features Allograft

PRISMA checklist
DOCX

DOCX

DOCX

DOCX

\section{References}

1. Howard K, Salkeld G, White S, McDonald S, Chadban S, Craig JC, Cass A (2009) The costeffectiveness of increasing kidney transplantation and home-based dialysis. Nephrology 14 (1):123132. doi:10.1111/j.1440-1797.2008.01073.x

2. Levey AS, Atkins R, Coresh J, Cohen EP, Collins AJ, Eckardt KU, Nahas ME, Jaber BL, Jadoul M, Levin A, Powe NR, Rossert J, Wheeler DC, Lameire N, Eknoyan G (2007) Chronic kidney disease as a global public health problem: approaches and initiatives - a position statement from Kidney Disease Improving Global Outcomes. Kidney international 72 (3):247-259. doi:10.1038/sj.ki.5002343 3. Critchley WR, Fildes JE (2012) Graft rejection - endogenous or allogeneic? Immunology 136 (2):123-132. doi:10.1111/j.1365-2567.2012.03560.x

4. Pawlus J, Sierocka A, Tejchman K, Zietek Z, Romanowski M, Pawlik A, Sienko J, Zukowski M, Ciechanowski K, Ostrowski M, Sulikowski T (2014) The impact of interleukin 12B (1188A>C), interleukin 16 (-295T>C), and interleukin 18 (607C >A, 137G>C) gene polymorphisms on long-term renal transplant function and recipient outcomes. Transplantation proceedings 46 (6):2079-2082. doi:10.1016/j.transproceed.2014.06.019 
5. Kruger B, Schroppel B, Murphy BT (2008) Genetic polymorphisms and the fate of the transplanted organ. Transplantation reviews 22 (2):131-140. doi:10.1016/j.trre.2007.12.002

6. Seeger H, Lindenmeyer MT, Cohen CD, Jaeckel C, Nelson PJ, Chen J, Edenhofer I, Kozakowski

N, Regele H, Boehmig G, Brandt S, Wuethrich RP, Heikenwalder M, Fehr T, Segerer S (2018)

Lymphotoxin expression in human and murine renal allografts. PloS one 13 (1):e0189396.

doi:10.1371/journal.pone.0189396

330 7. Wilson AG, Symons JA, McDowell TL, McDevitt HO, Duff GW (1997) Effects of a polymorphism in the human tumor necrosis factor alpha promoter on transcriptional activation. Proceedings of the National Academy of Sciences of the United States of America 94 (7):3195-3199.

doi:10.1073/pnas.94.7.3195

334 8. Herath S, Erlich J, Au AYM, Endre ZH (2019) Advances in Detection of Kidney Transplant Injury. Molecular diagnosis \& therapy 23 (3):333-351. doi:10.1007/s40291-019-00396-z

9. Phelan PJ, Conlon PJ, Sparks MA (2014) Genetic determinants of renal transplant outcome: where do we stand? Journal of nephrology 27 (3):247-256. doi:10.1007/s40620-014-0053-4

338 10. Liu Y, Lin N, Huang L, Xu Q, Pang G (2007) Genetic polymorphisms of the interleukin-18 gene and risk of prostate cancer. DNA and cell biology 26 (8):613-618. doi:10.1089/dna.2007.0600 11. Wei YS, Lan Y, Liu YG, Tang H, Tang RG, Wang JC (2007) Interleukin-18 gene promoter polymorphisms and the risk of esophageal squamous cell carcinoma. Acta oncologica 46 (8):10901096. doi:10.1080/02841860701373595

12. Borecki I (2001) Linkage and Association Studies. In: Encyclopedia of Life Sciences. John Wiley \& Sons, Ltd,

13. Lewontin RC (1988) On measures of gametic disequilibrium. Genetics 120 (3):849-852

14. Clark MF, Baudouin SV (2006) A systematic review of the quality of genetic association studies in human sepsis. Intensive Care Med 32 (11):1706-1712

15. Higgins JP, Thompson SG, Deeks JJ, Altman DG (2003) Measuring inconsistency in metaanalyses. Bmj 327 (7414):557-560

16. Higgins JP, Thompson SG (2002) Quantifying heterogeneity in a meta-analysis. Stat Med 21 (11):1539-1558

17. Mantel N, Haenszel W (1959) Statistical aspects of the analysis of data from retrospective studies of disease. J Natl Cancer Inst 22 (4):719-748

18. DerSimonian R, Laird N (1986) Meta-analysis in clinical trials. Control Clin Trials 7 (3):177-188

19. Galbraith RF (1988) A note on graphical presentation of estimated odds ratios from several clinical trials. Stat Med 7 (8):889-894

20. Kim CD, Ryu HM, Choi JY, Choi HJ, Choi HJ, Cho JH, Park SH, Won DI, Kim YL (2008)

Association of G-137C IL-18 promoter polymorphism with acute allograft rejection in renal transplant recipients. Transplantation 86 (11):1610-1614. doi:10.1097/TP.0b013e31818870c4

21. Mittal RD, Srivastava P, Singh V, Jaiswal P, Kapoor R (2011) Association of common variants of vascular endothelial growth factor and interleukin-18 genes with allograft survival in renal transplant recipients of North India. DNA and cell biology 30 (5):309-315. doi:10.1089/dna.2010.1138 22. Kolesar L, Novota P, Krasna E, Slavcev A, Viklicky O, Honsova E, Striz I (2007) Polymorphism of interleukin-18 promoter influences the onset of kidney graft function after transplantation. Tissue antigens 70 (5):363-368. doi:10.1111/j.1399-0039.2007.00913.x

23. do Nascimento WG, Ciliao DA, Genre J, Gondim DD, Alves RG, Hassan ND, Lima FP, Pereira MG, Donadi EA, de Oliveira Crispim JC (2014) Genetic polymorphisms of Interleukin-18 are not associated with allograft function in kidney transplant recipients. Genetics and molecular biology 37 (2):343-349

24. Dumas-Mallet E, Button KS, Boraud T, Gonon F, Munafo MR (2017) Low statistical power in biomedical science: a review of three human research domains. Royal Society open science 4 (2):160254. doi:10.1098/rsos.160254

25. Chen Y, Dawes PT, Packham JC, Mattey DL (2011) Interaction between smoking and polymorphism in the promoter region of the VEGFA gene is associated with ischemic heart disease and myocardial infarction in rheumatoid arthritis. The Journal of rheumatology 38 (5):802-809. doi:10.3899/jrheum.101095

26. Striz I, Krasna E, Honsova E, Lacha J, Petrickova K, Jaresova M, Lodererova A, Bohmova R, Valhova S, Slavcev A, Vitko S (2005) Interleukin 18 (IL-18) upregulation in acute rejection of kidney allograft. Immunology letters 99 (1):30-35. doi:10.1016/j.imlet.2005.01.010

27. de Oliveira JG, Xavier PD, Sampaio SM, Tavares IS, Mendes AA (2002) The synthesis by fineneedle aspiration biopsy cultures of IL-7, IL-16 and IL-18 is significantly associated with acute

382 rejection in kidney transplants. Nephron 92 (3):622-628. doi:10.1159/000064106 
medRxiv preprint doi: https://doi.org/10.1101/2020.05.27.20101196; this version posted June 1, 2020. The copyright holder has placed this preprint (which was not certified by peer review) in the Public Domain. It is no longer restricted by copyright. Anyone can legally share, reuse, remix, or adapt this material for any purpose without crediting the original authors.

383 28. Hall IE, Yarlagadda SG, Coca SG, Wang Z, Doshi M, Devarajan P, Han WK, Marcus RJ, Parikh 384 CR (2010) IL-18 and urinary NGAL predict dialysis and graft recovery after kidney transplantation.

385 Journal of the American Society of Nephrology : JASN 21 (1):189-197. doi:10.1681/ASN.2009030264

386 
TABLE 1 Characteristics of the included studies in interleukin-18 associations with kidney transplantation outcomes

\begin{tabular}{llllllll}
\hline First author & {$[\mathrm{R}]$} & Year & Country & Ethnicity & $\begin{array}{l}\text { Age (years) mean } \pm \text { SD } \\
\text { RJ / NRJ }\end{array}$ & IL-18 SNPs & CB \\
\hline Kim & 20 & 2008 & Korea & Asian & $33.9 \pm 9.4 / 36.1 \pm 11.1$ & rs187238 & 10 \\
Mittal & 21 & 2011 & India & Asian & $33.2 \pm 12.6 / 38.2 \pm 11.1$ & rs187238, rs1946518 & 6 \\
Kolesar & 22 & 2007 & Czechlovakia & Caucasian & 49.6 (patients) & rs187238, rs1946518 & 7 \\
do Nascimento & 23 & 2014 & Brazil & Caucasian & $33.1 \pm 12.4 / 40.5 \pm 13.0$ & rs187238, rs1946518 & 7 \\
\hline
\end{tabular}


409 TABLE 2 Summary outcomes for associations of interleukin-18 polymorphisms with kidney transplantation outcomes

410

\begin{tabular}{cc}
\hline Test of association & Test \\
heterogeneity
\end{tabular}

\begin{tabular}{cc}
\hline Test of association & $\begin{array}{c}\text { Test of } \\
\text { heterogeneity }\end{array}$ \\
\hline
\end{tabular}

$\begin{array}{llllllllllllllll}n & \text { OR } & 95 \% \mathrm{CI} & P^{\mathrm{a}} & P^{\mathrm{b}} & \begin{array}{c}\mathrm{I}^{2} \\ (\%)\end{array} & \mathrm{AM} & n & \text { OR } & 95 \% \mathrm{CI} & P^{\mathrm{a}} & \begin{array}{c}\text { Effect of } \\ \text { outlier } \\ \text { treatment }\end{array}\end{array}$

\begin{tabular}{|c|c|c|c|c|c|c|c|c|c|c|c|c|c|c|c|c|c|c|}
\hline & \multicolumn{8}{|c|}{$\mathrm{PRO}$} & \multicolumn{8}{|c|}{ PSO } & Sig & Het \\
\hline GD & & & & & Status & & & & & & & & Status & & & & & \\
\hline $\mathrm{Rc}$ & 7 & 1.33 & $0.99-1.79$ & .06 & $h p$ & .12 & 41 & $\mathrm{Fe}$ & --- & --- & --- & --- & -- & --- & --- & --- & --- & --- \\
\hline Do & 7 & 1.24 & $0.93^{-1.65}$ & .14 & $h p$ & .03 & 57 & $\operatorname{Re}$ & 6 & 1.39 & $1.13-1.70$ & $.002 \star$ & $h p$ & .23 & 28 & $\mathrm{Fe}$ & GS & $\mathrm{RH}$ \\
\hline $\mathrm{Co}$ & 7 & 1.17 & $0.96-1.44$ & .12 & $h p$ & .04 & 54 & $\mathrm{Re}$ & 5 & 1.34 & $1.13-1.58$ & $.0007 \star$ & $h p$ & .22 & 31 & $\mathrm{Fe}$ & GS & RH \\
\hline Allograft & & & & & Risk & & & & & & & & Risk & & & & & \\
\hline $\mathrm{Rc}$ & 7 & 0.84 & $0.55^{-1.29}$ & .43 & $d e$ & .14 & 38 & $\mathrm{Fe}$ & --- & -- & --- & --- & --- & --- & --- & --- & --- & --- \\
\hline Do & 7 & 0.74 & $0.55-0.98$ & .04 & $d e$ & .46 & o & $\mathrm{Fe}$ & --- & --- & --- & --- & --- & --- & --- & --- & --- & --- \\
\hline $\mathrm{Co}$ & 7 & 0.89 & $0.63^{-1.25}$ & .48 & $d e$ & .02 & 60 & $\operatorname{Re}$ & 5 & 0.73 & $0.56-0.93$ & $.01 \star$ & $d e$ & .16 & 39 & $\mathrm{Fe}$ & GS & $\mathrm{RH}$ \\
\hline
\end{tabular}

GD, genotype distribution; Rc, recessive; Do, dominant; Co, co dominant; $n$, number of studies; OR, odds ratio; CI, confidence interval; $P$ a,$P$-value for association; in, increased risk; de, decreased risk; hp, higher in patients; $P \mathrm{~b}, P$-value for heterogeneity (Het); $\mathrm{I}^{2}$, measure of variability; AM, analysis model; Re, random-effects; Fe, fixed-effects; PRO, pre-outlier; PSO, post-outlier; GS, gained Sig; RH, reduced Het; values in bold indicate Sig associations; $\star$ core outcome. 
430 TABLE 3 Subgroup outcomes for associations of interleukin-18 polymorphisms with kidney transplantation outcomes

\begin{tabular}{cc}
\hline Test of association & $\begin{array}{c}\text { Test of } \\
\text { heterogeneity }\end{array}$ \\
\hline
\end{tabular}

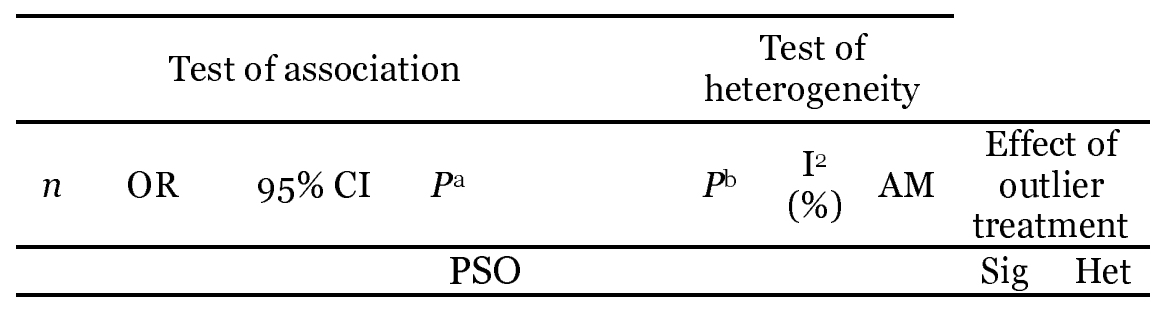

\begin{tabular}{|c|c|c|c|c|c|c|c|c|c|c|c|c|c|c|c|c|c|c|}
\hline & & & & $\mathrm{PR}$ & & & & & & & & PSO & & & & & $\mathrm{Sig}$ & Het \\
\hline GD & & & & & & & & & & & & & & & & & & \\
\hline Asian & & & & & Status & & & & & & & & Status & & & & & \\
\hline $\mathrm{Rc}$ & 3 & 1.47 & $0.71-3.04$ & .29 & $h p$ & 0.09 & 58 & $\operatorname{Re}$ & 2 & 1.25 & $0.76-2.04$ & .38 & $h p$ & .16 & 49 & $\mathrm{Fe}$ & RNS & RH \\
\hline Do & 3 & 1.12 & $0.71-1.77$ & .62 & $h p$ & 0.03 & 71 & $\operatorname{Re}$ & 2 & 0.90 & $0.67-1.22$ & .51 & $h c$ & .16 & 50 & $\mathrm{Fe}$ & RNS & RH \\
\hline Co & 3 & 1.17 & $0.86-1.60$ & .32 & $h p$ & 0.07 & 63 & $\operatorname{Re}$ & 2 & 0.99 & $0.78-1.26$ & .94 & $h c$ & .69 & 0 & $\mathrm{Fe}$ & RNS & $\mathrm{EH}$ \\
\hline Cauca & & & & & & & & & & & & & & & & & & \\
\hline $\mathrm{Rc}$ & 4 & 1.09 & $0.70-1.67$ & .71 & $h p$ & 0.25 & 26 & $\mathrm{Fe}$ & --- & --- & --- & --- & --- & --- & --- & --- & --- & --- \\
\hline Do & 4 & $\mathbf{1 . 3 7}$ & 1.04-1.80 & .03 & $h p$ & 0.11 & 50 & $\mathrm{Fe}$ & --- & --- & --- & --- & --- & --- & --- & --- & --- & --- \\
\hline $\mathrm{Co}$ & 4 & 1.17 & $0.86-1.61$ & .32 & $h p$ & 0.06 & 60 & $\operatorname{Re}$ & 3 & 1.32 & $1.04-1.66$ & .02 & $h p$ & .16 & 40 & $\mathrm{Fe}$ & GS & RH \\
\hline Allogr & & & & & & & & & & & & & & & & & & \\
\hline Asian & & & & & Risk & & & & & & & & Risk & & & & & \\
\hline $\mathrm{Rc}$ & 5 & 0.87 & $0.38-2.00$ & .75 & de & 0.05 & 58 & $\operatorname{Re}$ & 4 & 0.62 & $0.35^{-1.10}$ & .10 & de & .12 & 49 & $\mathrm{Fe}$ & RNS & RH \\
\hline Do & 5 & 0.70 & $0.50-0.98$ & .04 & de & 0.25 & 25 & $\mathrm{Fe}$ & --- & --- & --- & --- & --- & --- & --- & --- & --- & --- \\
\hline $\mathrm{Co}$ & 5 & 0.78 & $0.5^{2-1.16}$ & .22 & de & 0.05 & 58 & $\operatorname{Re}$ & 4 & 0.70 & $0.53-0.92$ & $.01 \star$ & de & .10 & 52 & $\mathrm{Fe}$ & GS & RH \\
\hline Cauca & & & & & & & & & & & & & & & & & & \\
\hline $\mathrm{Rc}$ & 2 & 0.88 & $0.35^{-2.20}$ & .78 & de & 0.82 & 0 & $\mathrm{Fe}$ & --- & --- & --- & --- & --- & --- & --- & --- & --- & --- \\
\hline Do & 2 & 0.85 & $0.50-1.47$ & .57 & de & 0.73 & o & $\mathrm{Fe}$ & --- & --- & --- & --- & --- & --- & --- & --- & --- & --- \\
\hline $\mathrm{Co}$ & 2 & 1.20 & $0.82-1.75$ & .35 & in & 0.10 & 63 & $\mathrm{Fe}$ & --- & --- & --- & --- & --- & --- & --- & --- & --- & --- \\
\hline
\end{tabular}
GD, genotype distribution; Rc, recessive; Do, dominant; Co, co dominant; $n$, number of studies; OR, odds ratio; CI, confidence interval; $P^{\mathrm{a}}, P$-value for association; hp, higher in
patients; hc, higher in controls; in, increased risk; de, decreased risk; $P$ b $P$-value for heterogeneity (Het); $\mathrm{I}^{2}$, measure of variability; AM, analysis model; Re, random-effects; Fe, fixed-effects; PRO, pre-outlier; PSO, post-outlier; GS, gained significance (Sig); RNS, retained non- Sig; RH, reduced Het; EH, eliminated Het; values in bold indicate Sig associations; $\star$ core outcome 
Interleukin-18 figure captions and legends

Figure 1 Summary flowchart of literature search

Figure 2 Forest plot outcome in the allograft analysis of the codominant model

Diamond denotes the pooled odds ratio (OR) indicating reduced risk (0.89). Squares indicate the OR in each study. $m$, match. Horizontal lines on either side of each square represent the $95 \%$ confidence intervals $(\mathrm{CI})$. The $\mathrm{Z}$ test for overall effect was non-significant $\left(P^{\mathrm{a}}=.48\right)$. The $x^{2}$-test shows the presence of heterogeneity $\left(P^{\phi}=.02, \mathrm{I}^{2}=60 \%\right) ; \mathrm{I}^{2}$, a measure of variability expressed in \%

Figure 3 Galbraith plot of the allograft analysis in the codominant model

m, match; Log OR, logarithm of standardized odds ratio; SE, standard error. The two studies above the +2 confidence limit are the outliers.

Figure 4 Forest plot outcome of outlier treatment in the allograft analysis of the codominant model

Diamond denotes the pooled odds ratio (OR) reduced risk (0.73). Squares indicate the OR in each study. $m$, match. Horizontal lines on either side of each square represent the $95 \%$ confidence intervals $(\mathrm{CI})$. The $Z$ test for overall effect shows significance $\left(P^{\mathrm{a}}=.01\right)$. The $\chi^{2}$ test indicates reduced heterogeneity $\left(P^{b}=.16, \mathrm{I}^{2}=39 \%\right) ; \mathrm{I}^{2}$, a measure of variability expressed in \% 


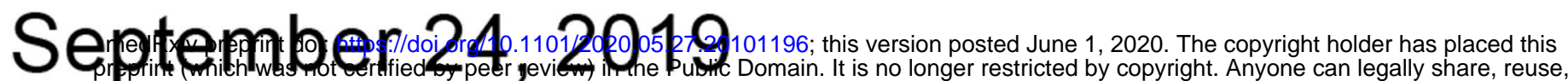

"interleukin", "IL-18", "cytokine", "polymorphism", "allograft" and "kidney transplantation"

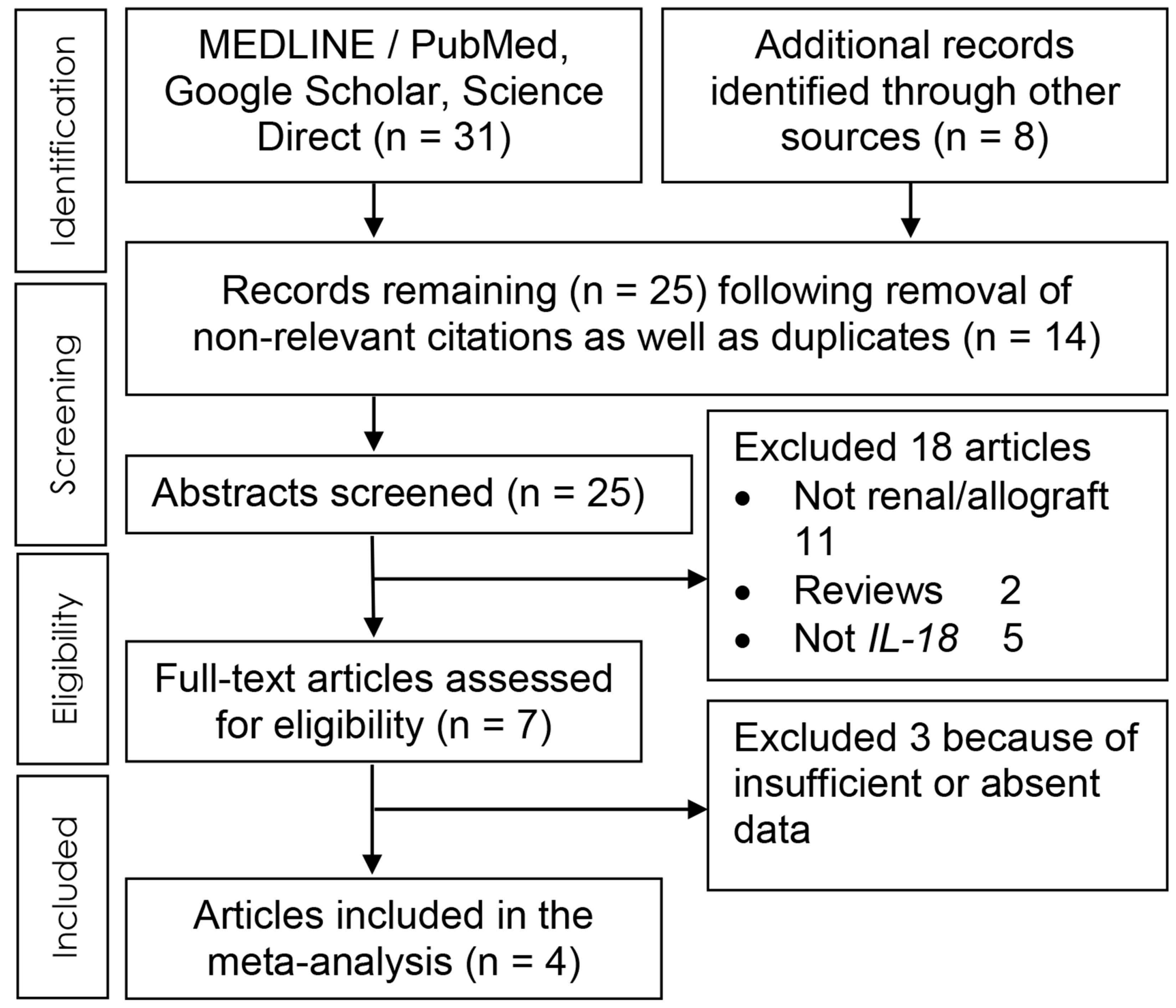


Case Control

Odds Ratio

Odds Ratio

Study rs number Events Total Events Total

Kim rs187238

Kolesar rs187238

Kolesar rs1946518

Mittal rs187238

Mittal rs187238m

Mittal rs1946518

Mittal rs1946518m

Total $(95 \% \mathrm{Cl})$

Total events

Heterogeneity: $\tau^{2}=0.13 ; \chi^{2}=15.16, d f=6\left(P^{b}=0.02\right) ; I^{2}=60 \%$

Test for overall effect: $Z=0.70\left(P^{a}=0.48\right)$

Random, 95\% Cl

Random, $95 \%$ Cl

$\begin{array}{rrrrrr}5 & 74 & 61 & 378 & 8.4 & 0.38[0.15,0.97] \\ 28 & 72 & 121 & 430 & 15.5 & 1.63[0.97,2.73] \\ 21 & 60 & 166 & 430 & 14.5 & 0.86[0.49,1.51] \\ 21 & 88 & 122 & 312 & 15.1 & 0.49[0.28,0.84] \\ 34 & 72 & 105 & 230 & 15.3 & 1.07[0.63,1.81] \\ 30 & 88 & 119 & 312 & 16.0 & 0.84[0.51,1.38] \\ 33 & 72 & 92 & 228 & 15.2 & 1.25[0.73,2.13] \\ & & & & & \\ 172 & & & & & \end{array}$

to

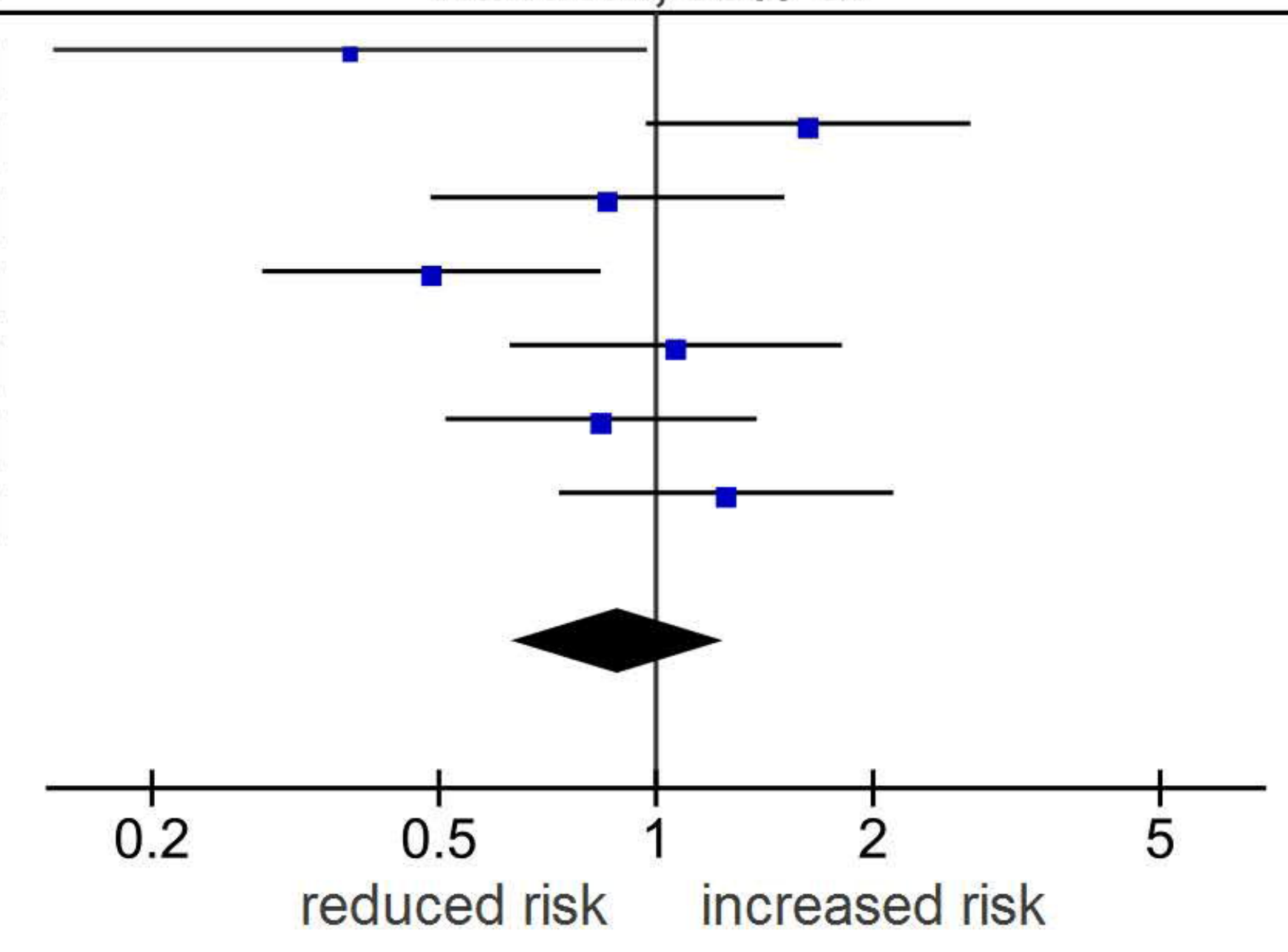




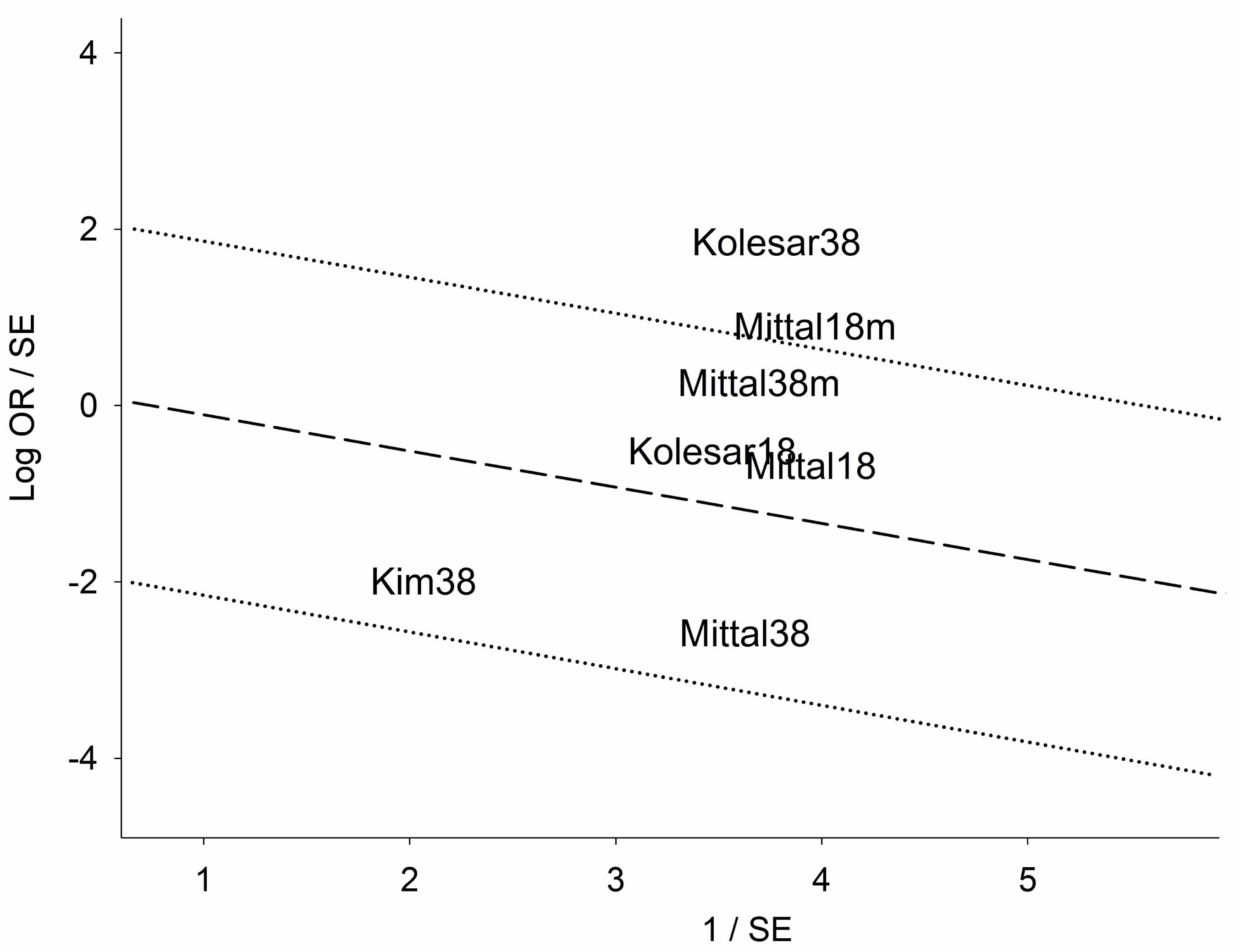


Odds Ratio

Study rs number Events Total Events Total

\section{Kim rs187238}

$\begin{array}{llll}5 & 74 & 61 & 378\end{array}$
$\%$ Fixed, 95\% Cl Fixed, 95\% Cl

Kolesar rs 1946518

Mittal rs187238

$\begin{array}{llll}21 & 60 & 166 & 430\end{array}$

12.7
$0.38[0.15,0.97]$

$\begin{array}{llll}21 & 88 & 122 & 312\end{array}$

$\begin{array}{llll}34 & 72 & 105 & 230\end{array}$

$30 \quad 88$

$119 \quad 312$

18.0

$0.86[0.49,1.51]$

27.8

$0.49[0.28,0.84]$

Mittal rs $187238 \mathrm{~m}$

Mittal rs1946518

Total $(95 \% \mathrm{Cl})$

382

1662

18.0

$1.07[0.63,1.81]$

23.5

$0.84[0.51,1.38]$

Total events

100.0

$0.73[0.56,0.93]$ 573

Heterogeneity: $\chi^{2}=6.57, \mathrm{df}=4\left(\mathrm{P}^{\mathrm{b}}=0.16\right) ; \mathrm{I}^{2}=39 \%$

Test for overall effect: $Z=2.49\left(P^{a}=0.01\right)$

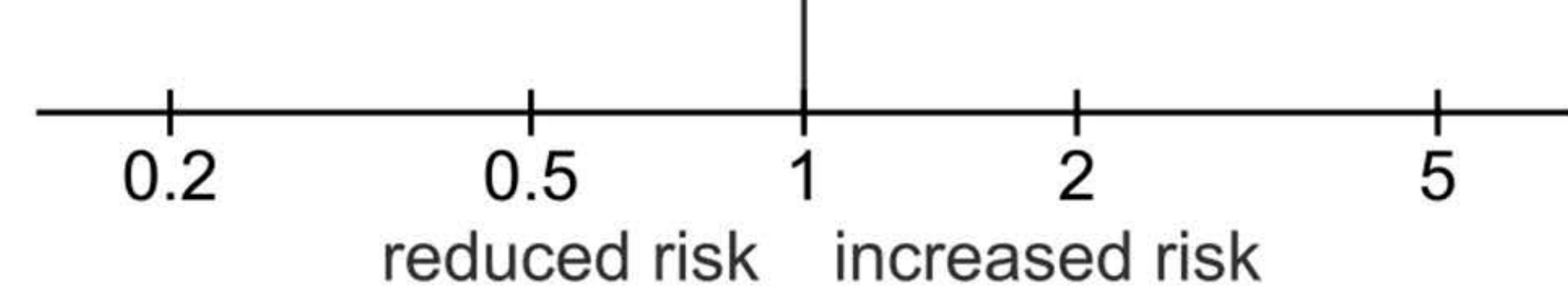

